University of Nebraska - Lincoln

DigitalCommons@University of Nebraska - Lincoln

Publications, Agencies and Staff of the U.S.

Department of Commerce

U.S. Department of Commerce

$1-2009$

\title{
Anthropogenic Scarring of Western Gray Whales (Eschrichtius robustus)
}

Amanda Bradford

University of Washington - Seattle Campus

David Weller

Southwest Fisheries Science Center, NOAA Fisheries

Yulia Ivaschenko

Kamchatka Branch of Pacific Institute of Geography, Far East Branch of the Russian Academy of Sciences, Pr. Rybakov, 19-a, Petropavlovsk-Kamchatsky, Russia

Alexander Burdin

Far East Branch of the Russian Academy of Sciences, Pr. Rybakov, 19-a, Petropavlovsk-Kamchatsky, Russia

Robert L. Brownell Jr.

Pacific Grove, California, rlbcetacea@aol.com

Follow this and additional works at: https://digitalcommons.unl.edu/usdeptcommercepub

Part of the Environmental Sciences Commons

Bradford, Amanda; Weller, David; Ivaschenko, Yulia; Burdin, Alexander; and Brownell, Robert L. Jr., "Anthropogenic Scarring of Western Gray Whales (Eschrichtius robustus)" (2009). Publications, Agencies and Staff of the U.S. Department of Commerce. 16.

https://digitalcommons.unl.edu/usdeptcommercepub/16

This Article is brought to you for free and open access by the U.S. Department of Commerce at DigitalCommons@University of Nebraska - Lincoln. It has been accepted for inclusion in Publications, Agencies and Staff of the U.S. Department of Commerce by an authorized administrator of DigitalCommons@University of Nebraska - Lincoln. 
MARINE MAMMAL SCIENCE, 25(1): 161-175 (January 2009)

\title{
Anthropogenic scarring of western gray whales (Eschrichtius robustus)
}

\author{
AMANDA L. BRADFORD \\ School of Aquatic and Fishery Sciences, \\ University of Washington, \\ P. O. Box 355020, \\ Seattle, Washington 98195-5020, U.S.A. \\ E-mail: alb992@u.washington.edu \\ DAVID W. WeLLER \\ Southwest Fisheries Science Center, NOAA Fisheries, \\ 8604 La Jolla Shores Drive, \\ La Jolla, California 92037-0271, U.S.A.

\section{Yulia V. IVASHCHENKO} \\ Kamchatka Branch of Pacific Institute of Geography, \\ Far East Branch of the Russian Academy of Sciences, \\ Pr. Rybakov, 19-a, \\ Petropavlovsk-Kamchatsky, 683024, Russia

\section{Alexander M. Burdin} \\ Kamchatka Branch of Pacific Institute of Geography, \\ Far East Branch of the Russian Academy of Sciences, \\ Pr. Rybakov, 19-a, \\ Petropavlovsk-Kamchatsky, 683024, Russia \\ and \\ Alaska SeaLife Center, \\ 301 Railway Avenue, \\ Seward, Alaska 99664, U.S.A. \\ and \\ University of Alaska Fairbanks, \\ P. O. Box 757500 , \\ Fairbanks, Alaska 99775, U.S.A. \\ ROBERT L. BROWNELL, JR. \\ Southwest Fisheries Science Center, NOAA Fisheries, \\ 1352 Lighthouse Avenue, \\ Pacific Grove, California 93950, U.S.A.
}

\begin{abstract}
Western gray whales (Eschrichtius robustus) are critically endangered and anthropogenic threats, such as entanglement in fishing gear and collisions with vessels, may be acting to limit recovery of the population. Thus, examining the magnitude
\end{abstract}


of such anthropogenic interactions using a scar-based approach is warranted. A multi-year (1995-2005) photo-identification study of western gray whales on their feeding ground off northeastern Sakhalin Island, Russia, has resulted in a large data set of digital and film images of 150 individuals. These images were reviewed and scored for anthropogenic scarring by recording the presence of visible scars resulting from fishing gear entanglement and vessel collisions in 21 defined body regions. In total, $20.0 \%(n=30)$ of whales identified during the study period had detectable anthropogenic scarring, with $18.7 \%(n=28)$ determined to have been previously entangled in fishing gear at least once and $2.0 \%(n=3)$ to have survived at least one vessel collision. These estimates are likely to be conservative given the nature of the photo-identification data set, but indicate that male and female western gray whales are subject to anthropogenic interactions. Future studies designed to systematically estimate the frequency and rates of anthropogenic events are needed and would have direct conservation and management implications.

Key words: anthropogenic scarring, entanglement, Eschrichtius robustus, photoidentification, species conservation, vessel collision, western gray whale.

The western population of gray whales (Eschrichtius robustus) is critically endangered (Hilton-Taylor 2000, Weller et al. 2002), having been nearly extirpated by modern commercial whaling operations from the late 19th to the mid 20th centuries (Brownell and Chun 1977, Weller et al. 2002). The most current mark-recapture analysis conducted estimated the population abundance to be $99(95 \% \mathrm{CI}=90-109)$ in 2003 (Bradford et al. 2008). A recent population assessment using an individualbased model fitted to the same data used in the mark-recapture study, but also including data from 2004 through 2006, estimated the median non-calf population size to be 110 in 2004 and, should current population and demographic trends continue, projected a median non-calf estimate of 121 (90\% Bayesian CI $=112-130$ ) in 2007 (Cooke et al. 2007). Western gray whales are at risk from factors threatening small populations and current anthropogenic threats, such as entanglement in fishing gear and collisions with vessels (Weller et al. 2002, Reeves et al. 2005), could compound this risk.

Fishing gear entanglement and vessel collisions pose a threat to baleen whale populations worldwide. In the case of western North Atlantic right whales (Eubalaena glacialis), mortality and serious injury from these sources have been linked to the failure of this endangered population to recover (Kraus 1990, Fujiwara and Caswell 2001, Knowlton and Kraus 2001, Kraus et al. 2005). The extent of these events, particularly of fishing gear entanglement, has also been well studied in western North Atlantic and, to a lesser extent, in eastern North Pacific humpback whales (Megaptera novaeangliae) (Lien 1994, Volgenau et al. 1995, Laist et al. 2001, Robbins and Mattila 2001, 2004, Johnson et al. 2005, Neilson 2006). For both species, much insight into the occurrence and, to some degree, impact of entanglement and vessel collisions has been gleaned from evaluating associated scarring of photo-identified individuals (Kraus 1990, Hamilton et al. 1998, Robbins and Mattila 2001, 2004, Knowlton et al. 2005, Neilson 2006).

Given their coastal distribution, both eastern and western gray whales are vulnerable to entanglement in fishing gear and collisions with vessels (Sumich and Harvey 1986, Heyning and Lewis 1990, Laist et al. 2001, Baird et al. 2002, Reeves et al. 2005), although the population-level consequences are more severe for the western 
population due to its critically endangered status. Assessing the extent of these events for western gray whales is of obvious conservation concern, particularly after the fatal entrapments of four female western gray whales in fishing gear off the Pacific coast of Japan, three in 2005 and one in 2007 (Weller et al., in press). An ongoing Russia-U.S. photo-identification study of western gray whales has been conducted on their feeding ground off the northeastern coast of Sakhalin Island, Russia since 1995 (Weller et al. 1999, 2002). Through 2005, this study has resulted in a large data set of digital and film images of 150 photo-identified individuals (Weller et al. 2006) that were used to examine and quantify nonlethal fishing gear entanglement and vessel collisions via a scar-based approach. Taking care to employ a quantification protocol that could be replicated by other researchers, the specific objectives of the scarring assessment were: (1) to estimate a minimum number of individuals that have survived at least one entanglement and/or vessel collision, and (2) to specify the body regions most indicative of these events. The overall aim of the analysis is to provide evidence that the western gray whale population is affected by anthropogenic risk factors and to serve as a foundation for future research.

\section{METHODS}

Beginning in 1997, following an opportunistic effort in 1994 and a pilot study in 1995, western gray whale photo-identification surveys were carried out annually during summer months off the northeastern coast of Sakhalin Island, Russia, in the nearshore waters proximate to Piltun Lagoon. For information about the study area and a detailed description of the photo-identification data collection and analysis protocols, see Weller et al. (1999). From 1994 to 2005, 307 photo-identification surveys were conducted, which resulted in 4,547 sightings of 150 individual whales. A sighting consisted of at least one high quality photo-identification image, although in most cases, several images were obtained. Additionally, 14 sightings of 11 of these individuals were collected in 2002 during a survey of an ephemeral feeding area approximately $60 \mathrm{~km}$ southeast of Piltun Lagoon (Burdin et al. 2002). Overall, 28,274 film and digital images from 4,561 sightings of 150 photo-identified western gray whales were utilized in the present scarring analysis. Note that the sex of 124 of these individuals is known from genetic analyses of biopsy samples collected in coordination with photo-identification efforts (Weller et al. 2006).

A protocol adapted from right whale researchers (Hamilton et al. 1998, Knowlton et al. 2005) was used to quantify anthropogenic scarring of western gray whales. The right whale scar quantification approach has been successfully employed in retrospective scarring assessments of photo-identification data (Hamilton et al. 1998, Knowlton et al. 2005). Since the aim of the methodology is to provide minimum estimates of anthropogenic interactions, the entire photo-identification data set can be utilized, even though: (1) photographic coverage is unequal across body regions within and between individuals, and (2) the target body region for photo-identification is not known to be particularly vulnerable to scarring. The right whale system contrasts with the scar-based method that has been refined by humpback whale researchers to systematically evaluate entanglement, where only standardized images of the lateral caudal peduncle during fluke-up dives are scored for scars (Robbins and Mattila 2001, 2004, Neilson 2006). The caudal peduncle is not used in individual identification of humpback whales, but it is especially susceptible to entanglement (Johnson $e t$ al. 2005). The benefit of this type of protocol is that photographic coverage is relevant, 
consistent, and comparable for all individuals, which allows for a more precise determination of the frequency and rates of nonlethal exposure to entanglement at the individual and population levels. A drawback to this approach is that it can limit the scope and sample size of retrospective reviews of photo-identification data sets, particularly for populations where scars from more than one type of interaction are of interest and where the body regions most vulnerable to scarring have not yet been established.

Therefore, for the first assessment of anthropogenic scarring of western gray whales, the broad-based right whale quantification approach was utilized. That is, all available images of an individual whale were examined for the presence of anthropogenic scars in 21 defined regions spanning the entire body (Fig. 1). Specifically, for each survey sighting of a whale, one or more of the designated codes (Table 1) were assigned to all body regions of that individual. Thus, a line of recorded data consisted of 21 cells, each comprised of one or more codes indicating if the body region of that whale during that sighting was either: (1) without scarring; (2) with entanglement, vessel collision, and/or unknown scarring (Fig. 2); (3) partially visible with or without scarring; or (4) not visible. These data for each survey sighting were then collapsed in order to produce an annual scar composite of each whale for use in subsequent summaries and analyses. An annual scar composite was thus one line of data containing all information (i.e., presence of scarring and degree of visibility) gleaned about each body region of a whale during a given year. Note that while the described protocol systematically quantified the presence of anthropogenic scarring, it could not enumerate scarring events.

All coding was conducted by one analyst (ALB), as recommended for consistency in scarring analyses (Neilson 2006). However, an interrater agreement study was performed to determine if the western gray whale scar quantification protocol could be used by more than one qualified researcher to achieve similar results. That is, images from a subset of 300 randomly selected sightings were reviewed by a second analyst (YVI), who coded all body regions of the 98 individuals represented in the subset. Corresponding data from the two researchers were then compared in four separate tests of interrater agreement, which was measured using the kappa $(\kappa)$ coefficient (Cohen 1960), where $\kappa>0.75$ is strong agreement, $0.75>\kappa>0.40$ is good-to-moderate agreement, and $\kappa<0.40$ is fair-to-poor agreement (e.g., Simonoff 2003). First, the decision to code each body region per sighting as visible (non-X) or not visible $(\mathrm{X})$ was evaluated over all scoring opportunities. Next, when both analysts coded a body region as visible, the choice to code as fully visible (non-P) or partially visible $(\mathrm{P})$ was examined. The third and fourth tests assessed agreement in the resulting scar code when the two researchers coded a body region as partially visible or fully visible, respectively. For these latter two tests, entanglement and vessel collision scar codes were pooled for sample size considerations, such that the judgment to code no scar $(\mathrm{N})$, unknown scar $(\mathrm{U})$, or anthropogenic scar $(\mathrm{A})$ was evaluated. For each of the four tests, the underlying prevalence of the observed entities was expected to be highly imbalanced (e.g., more $\mathrm{X}$ body regions than non$\mathrm{X}$ ), which can lead to low values of $\kappa$ despite relatively high values of total agreement (Feinstein and Cicchetti 1990). Thus, for each test, the proportional agreement $(p)$ of each unit $\left(e . g ., p_{\text {non-X }}, p_{\mathrm{X}}\right)$ was reported along with $\kappa$ as a recommended supplemental diagnostic (Cicchetti and Feinstein 1990).

For both the right and humpback whale methodologies, researchers have been able to validate the sources of anthropogenic scars from observations of scars obtained from known cases of both lethal and nonlethal fishing gear entanglements and vessel collisions (e.g., Kraus 1990, Robbins and Mattila 2001). This type of 

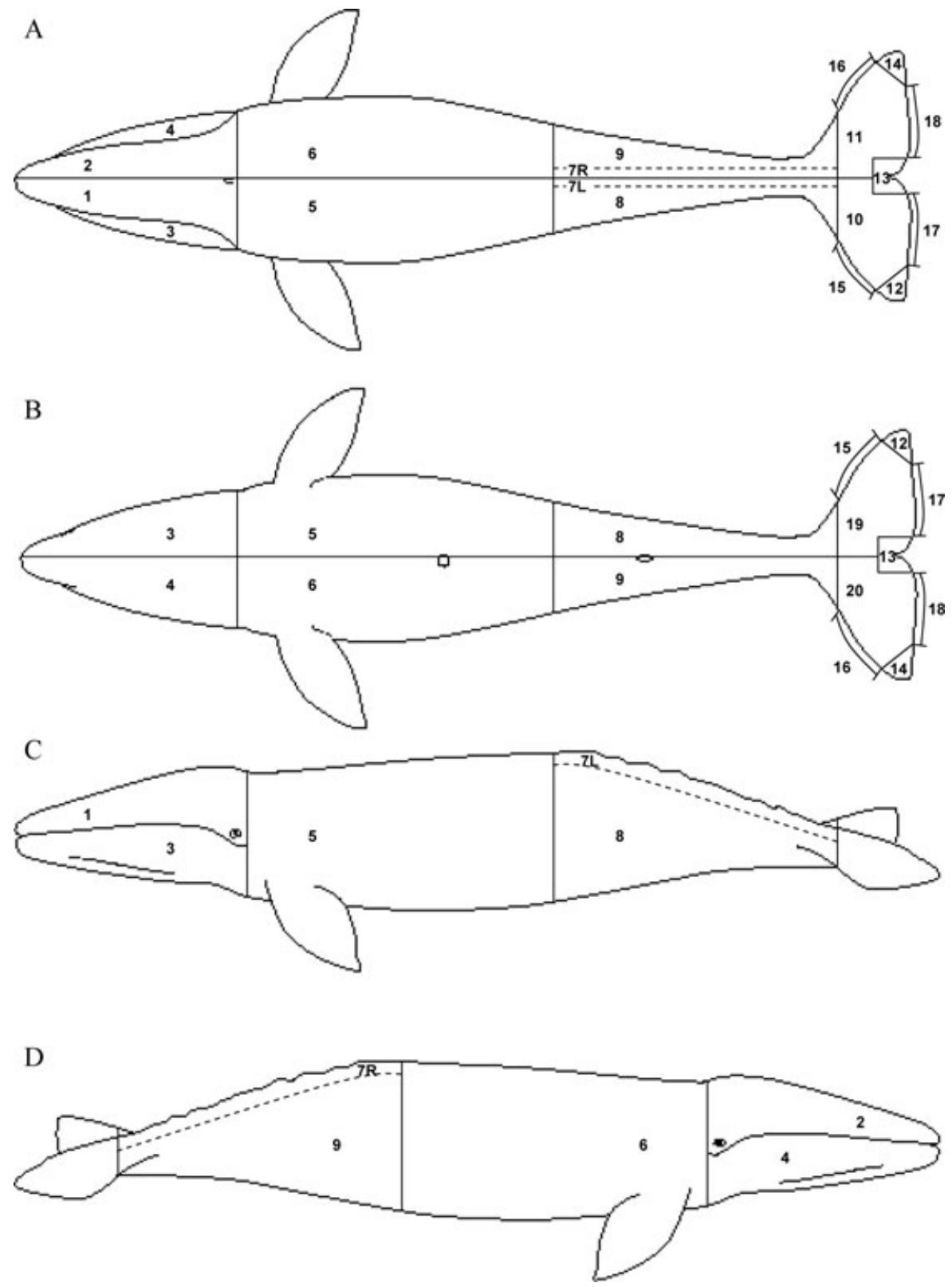

Figure 1. Dorsal (A), ventral (B), left side (C), and right side (D) views of western gray whale body regions $(n=21)$ examined for possible scarring. Note that while body regions are numbered 1 through 20, number 7 is divided into separate right $(\mathrm{R})$ and left $(\mathrm{L})$ regions. Gray whale outlines courtesy of J. L. Sumich. 
Table 1. Scar codes assigned to western gray whale body regions during image analysis (adapted from Hamilton et al. 1998).

\begin{tabular}{|c|c|c|}
\hline Code & Definition & Description \\
\hline $\mathrm{N}$ & No scar & No scars visible. \\
\hline & New scar & $\begin{array}{l}\text { Used in combination with another scar code to indicate the } \\
\text { first sighting of a scar. }\end{array}$ \\
\hline $\mathrm{E}$ & Entanglement & $\begin{array}{l}\text { Linear furrows or chafing that appear to wrap around the } \\
\text { body. }\end{array}$ \\
\hline V & Vessel collision & $\begin{array}{l}\text { Scars that appear the result of propeller wounds or severe } \\
\text { physical trauma. }\end{array}$ \\
\hline $\mathrm{U}$ & Unknown scar & $\begin{array}{l}\text { Marks seemingly unrelated to barnacle scarring that cannot } \\
\text { be assigned to the other scar categories. }{ }^{\text {a }}\end{array}$ \\
\hline $\mathrm{P}$ & Partially visible & $\begin{array}{l}\text { Used in combination with another scar code to denote that } \\
\text { the body region is only partially photographed or is too } \\
\text { dark, out of focus, or distant in the image to completely } \\
\text { assess scarring. }\end{array}$ \\
\hline $\mathrm{X}$ & Not visible & $\begin{array}{l}\text { Body region was not photographed at all or is too dark, out } \\
\text { of focus, or distant in the image to assess scarring. }\end{array}$ \\
\hline
\end{tabular}

\footnotetext{
${ }^{a}$ Killer whale (Orcinus orca) rake marks were also quantified, but these findings are not discussed in this article.

${ }^{\mathrm{b}}$ The ventral portions of the following body regions (BR) were assumed never to be visible: BR5, BR6, BR8, and BR9. Thus, the P code was not assigned in these regions unless parts of the dorsal surface were obscured or not photographed.
}

validation, though of importance, is not yet possible for scarring assessments of western gray whales. Anthropogenic scar determinations in the present analysis were based on images and descriptions from other baleen whale studies (Kraus 1990, Philo et al. 1992, George et al. 1994, Hamilton et al. 1998, Robbins and Mattila 2001, 2004, Moore et al. 2004, Knowlton et al. 2005, Neilson 2006, Panigada et al. 2006), with the recognition that the species, individual, behavior, location, duration, gear type, and vessel involved collectively influence the degree and nature of potential scarring during a given interaction. Thus, the present western gray whale anthropogenic scar codes were assigned with an unavoidable level of inherent subjectivity. Therefore, for evaluative purposes, these scar assignments were reviewed by three independent reviewers with specific expertise in analyzing right or humpback whale anthropogenic scarring that has been validated by observations. For each western gray whale considered to have incurred anthropogenic scarring, the reviewers were asked to respond to the following two questions: (1) are the highlighted scars consistent with fishing gear entanglement (and/or vessel collision), and (2) would you support a determination that this whale was previously entangled (and/or struck by a vessel)?

\section{RESULTS}

\section{Interrater Agreement}

The randomly selected subset of 300 sightings representing 98 photo-identified western gray whales resulted in 6,300 scoring opportunities from which to measure interrater agreement. For the decision to code each body region per sighting as visible 

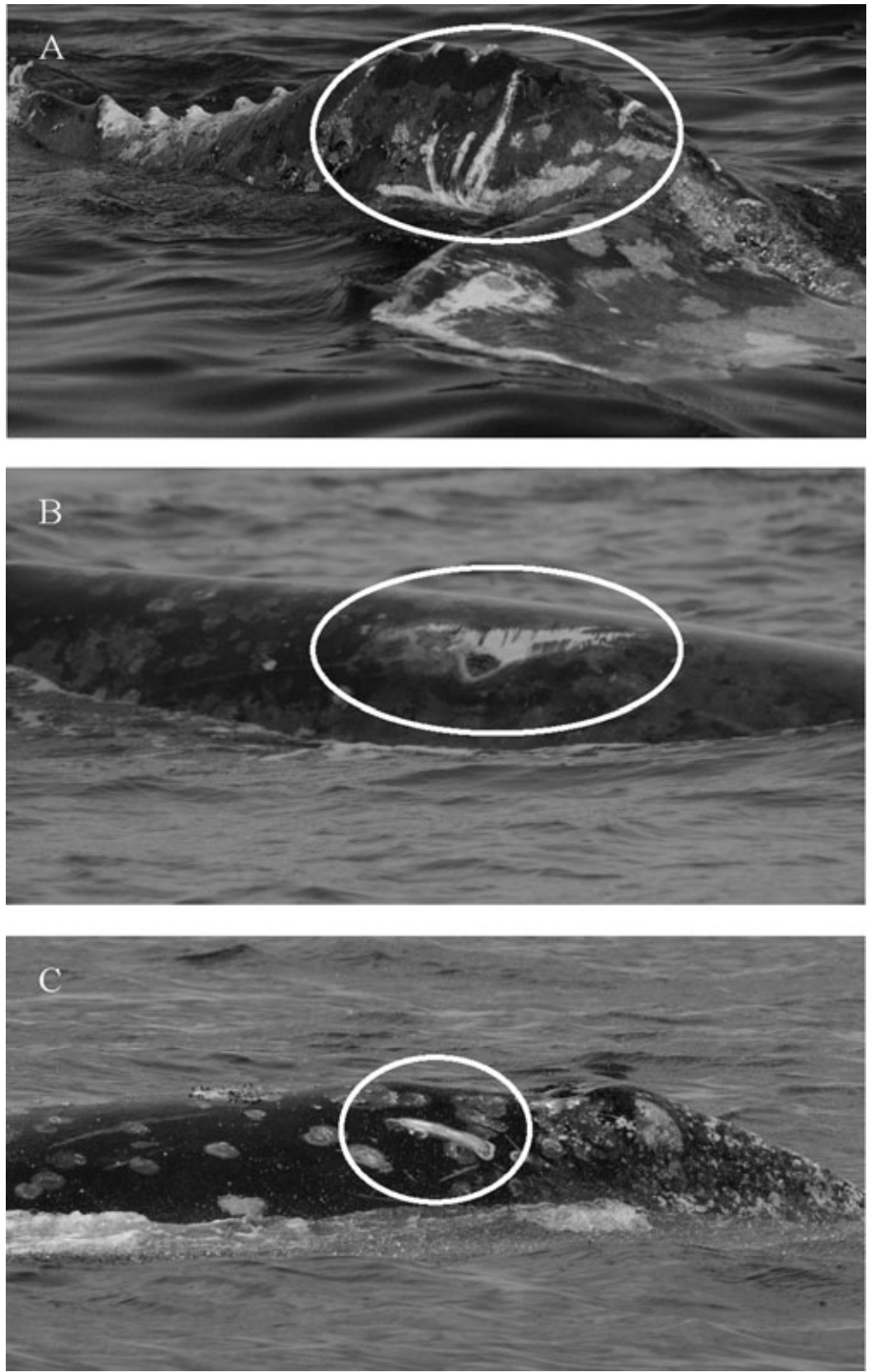

Figure 2. Example images of individual western gray whales with scarring (circled) from a presumed fishing gear entanglement (A), vessel collision (B), and unknown source (C), corresponding to scar codes E, V, and U, respectively (Table 1). Photos by D. W. Weller. 
or not visible, $\mathrm{\kappa}$ indicates strong agreement and both values of $p$ are high, especially for the not visible determinations $\left(\kappa=0.81, p_{\text {non }-\mathrm{X}}=0.84, p_{\mathrm{X}}=0.97, n=6,300\right)$. For the choice to code visible body regions as either fully or partially visible, $\kappa$ denotes good agreement and both values of $p$ are again high, particularly for the partially visible assignments $\left(\kappa=0.74, p_{\text {non }-\mathrm{P}}=0.80, p_{\mathrm{P}}=0.94, n=735\right)$. For the resulting scar code in partially visible body regions, $\kappa$ shows moderate agreement, while $p$ is high for the no scar designations and considerably lower for the unknown and anthropogenic categories $\left(\kappa=0.43, p_{\mathrm{N}}=0.94, p_{\mathrm{U}}=0.47, p_{\mathrm{A}}=0.41, n=519\right)$. For the ensuing scar code in fully visible body regions, $\kappa$ demonstrates good agreement and $p$ values are high except in the case of the unknown scar determinations $\left(\kappa=0.62, p_{\mathrm{N}}=0.97\right.$, $\left.p_{\mathrm{U}}=0.36, p_{\mathrm{A}}=0.91, n=145\right)$. Overall, $\mathrm{\kappa}$ generally declined as the sample size of each test decreased and values of $p$ were consistently higher for the more prevalent observed entities within each test.

\section{Anthropogenic Scarring}

The 4,561 survey sightings were collapsed into 681 annual scar composites representing 150 photo-identified western gray whales, with a median of four composites per whale (range $=1-11$ ). The degree of usable image coverage varied by body region, with the greatest frequency of coverage in the body regions (BR) that encompass the photo-identification target feature (i.e., BR5, BR6, BR7L, BR7R, BR8, and BR9), although these regions were most often not fully visible (Fig. 3).

Of the 150 photo-identified western gray whales, 30 (20.0\%; 15 males, 14 females, one of unknown sex) individuals were assigned at least one anthropogenic scar code in at least one body region from 1994 to 2005 , with $28(18.7 \% ; 15,12,1)$ whales presumed to have been previously entangled in fishing gear at least once and three $(2.0 \% ; 1,2,0)$ to have survived at least one vessel collision. One male appeared to have previously experienced at least one entanglement and one or more vessel collisions. Of the 28 whales with entanglement scars, at least $11(39.3 \%, 8,3,0)$ were $3 \mathrm{yr}$ of age or younger when their scars were acquired (none of the individuals with vessels scars are of known age). For 11 anthropogenic interactions involving

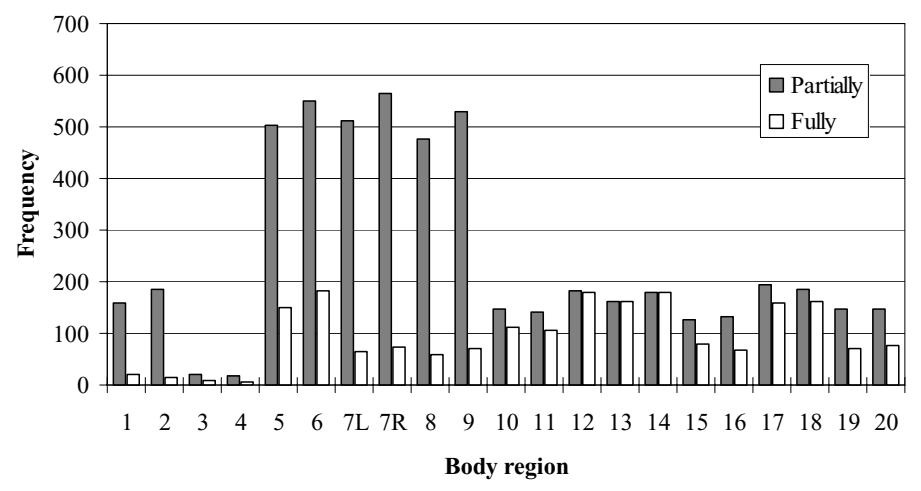

Figure 3. Frequency of partially and fully visible body regions represented in the annual scar composites $(n=681)$ of 150 western gray whales from 1994 to 2005 . Note that photographic coverage by body region varied within and between individuals and that individual whales were often identified in multiple years. 


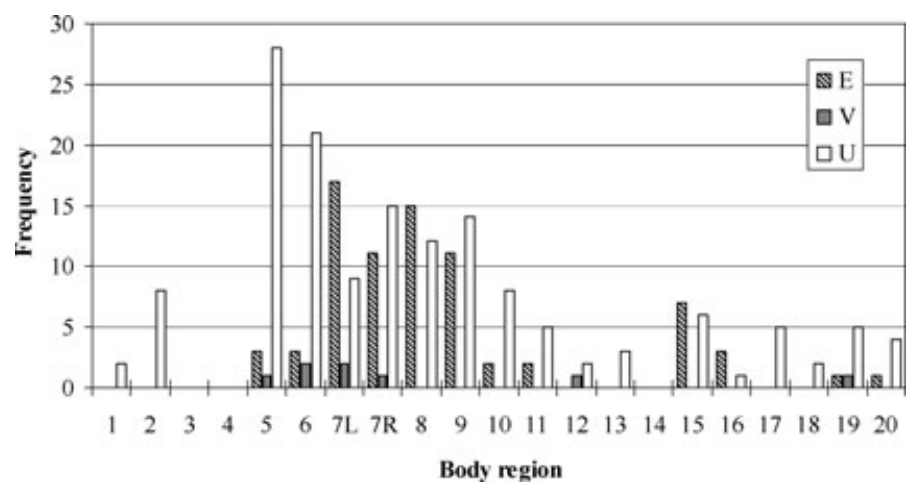

Figure 4. Frequency of entanglement (E), vessel collision (V), and unknown (U) scar codes $(n=234 ; 76 \mathrm{E}, 8 \mathrm{~V}, 150 \mathrm{U}$ ) by body region for 150 western gray whales from 1994 to 2005 . Note that while repeated observations of the same scar and multiple scars of the same type within a body region are represented only once per individual, individual whales can have more than one scar type per body region and can have the same scar code across multiple body regions.

nine whales, the annual timing of the event was determined (i.e., when a body region was coded as fully visible without the scar in the year preceding a new anthropogenic scar designation or when the scarred individual was a calf). Of these occurrences, the presumed entanglements occurred in the months prior to the $1997(n=1), 1998$ $(n=3), 2000(n=1), 2001(n=1), 2002(n=1), 2003(n=3)$ field seasons and the assumed vessel collision before $2001(n=1)$ and $2001(n=1)$.

Most of the entanglement scar assignments were attributed to the left and right caudal peduncle (i.e., BR7L, BR7R, BR8, and BR9) followed by the leading edges of the flukes (i.e., BR15 and BR16), while the majority of vessel collision scars were found on the back and dorsal ridge (BR5, BR6, BR7L, and BR7R) (Fig. 4). Unknown scars were detected in nearly all body regions, although the greatest numbers were located on the back and sides (BR5 and BR6) (Fig. 4).

\section{Expert Review}

When considered collectively, the three independent expert reviewers confirmed most of the anthropogenic scar assignments, although there was noticeable variation between the reviewers. Specifically, of the 28 whales assumed to have been entangled, $12(42.9 \%)$ of the cases were supported (i.e., an affirmative response provided to both posed questions) by all three, $22(78.6 \%)$ by at least two, and $25(89.3 \%)$ by at least one of the analysts. Of the three whales presumed to have survived a vessel collision, none of the cases were corroborated by two or more reviewers, but all three $(100.0 \%)$ were substantiated once.

\section{DisCUSSION}

\section{Interrater Agreement and Expert Review}

Interrater agreement in the four tests was strong to moderate as measured by $\kappa$. However, $\kappa$ values are likely biased low given substantial imbalances in prevalence 
of the observed entities (Feinstein and Cicchetti 1990), a suggestion that is generally supported by values of the $p$ diagnostic. Agreement was strongest for the decisions to code each body region per sighting as visible or not visible and to code the visible regions as either fully or partially visible, indicating that the two analysts mutually conceptualized the 21 body regions and made similar basic judgments about the extent and quality of photographic coverage. Agreement was weakest for the choice of scar code in the partially visible body regions, although the reduced agreement in this test may not have been due solely to discrepancies in scar assignments, but also to different interpretations of partial photographic coverage. Unsurprisingly, agreement in scar coding improved when both raters considered a body region to be fully visible. Further, $p_{\mathrm{A}}$ is high in this case indicating that anthropogenic scars were commonly perceived and detected by both researchers. This perception of anthropogenic scarring was generally supported by the expert review process. However, the variation within expert opinion demonstrates that subjectivity in scar assessment can be minimized by validation and experience, but likely not completely eliminated. In summary, the western gray whale scar quantification protocol can be used by more than one trained researcher to produce comparable results that would largely be consistent with expert opinion.

\section{Antbropogenic Scarring}

Image coverage was available to quantify scarring in all body regions, although the amount varied by body region (Fig. 3). The greatest frequency of coverage was obtained in the body regions encompassing the photo-identification target feature (i.e., the dorsal flanks). Specifically, given the ideal photo-identification image (Weller et al. 1999), the most coverage was achieved in the posterior portions of BR5 and BR6 and the anterior portions of $\mathrm{BR} 7 \mathrm{~L}, \mathrm{BR} 7 \mathrm{R}, \mathrm{BR} 8$, and $\mathrm{BR} 9$, which is reflected by the high percentage of partial coverage in those regions (Fig. 3). Another representation of photo-identification effort is that within these regions, coverage percentages are relatively higher for the right-side regions (i.e., BR6, BR7R, and BR9) than the corresponding left-side regions (i.e., BR5, BR7L, and BR8, respectively) (Fig. 3), which reflects the higher priority of collecting right-side dorsal flank images (Weller et al. 1999). These findings are not surprising given the intended function (i.e., reliable individual recognition) of the photographic data set.

In contrast to other baleen whale studies, a relatively smaller percentage of photoidentified western gray whales were determined to have anthropogenic scarring, with estimates of $18.7 \%$ for fishing gear entanglement and $2.0 \%$ for vessel collision. For example, $75.6 \%$ and $6.4 \%$ of photo-identified North Atlantic right whales bore scars from entanglement and ship strikes, respectively (Hamilton et al. 1998, Knowlton et al. 2005). Also, annual estimates of photo-identified Gulf of Maine humpback whales exhibiting entanglement scars ranged from $47.8 \%$ to $64.6 \%$ (Robbins and Mattila 2001). While anthropogenic interactions are expected to vary by population and geographic region, it is likely that the estimates presented here underestimate the true proportion of western gray whales that have experienced these events, given the nature of the available data set. That is, image coverage was not comprehensive for every individual in all years, indicating that anthropogenic scars on some whales could have been missed during the scarring assessment. Also, the feature targeted for photo-identification excludes portions of body regions that have been found to be susceptible to anthropogenic scarring in other baleen whale populations. Specifically, 
the anterior portion of the back can be struck by ships (e.g., Knowlton and Kraus 2001) and the posterior portion of the caudal peduncle along with the leading edges of the flukes are particularly vulnerable to entanglement scarring (e.g., Heyning and Lewis 1990, Johnson et al. 2005). Given the low photographic coverage in these regions (Fig. 3), combined with the fact that scars were observed in apparently less vulnerable, but more photographed regions, suggests that some evidence of anthropogenic interactions was likely undetected, both at the individual and population levels. Further, the majority of scars discerned in the analysis were coded as unknown and these scars were found in nearly all body regions, particularly those regions where anthropogenic scars were also detected (Fig. 4). Conceivably, some of these scars represent inconclusive or incomplete evidence of an entanglement or vessel collision. Additionally, previous events may not have left external scars or resulting scars may have healed by the time the associated body region was photographed, which would have further underestimated actual anthropogenic interaction percentages.

The western gray whale body regions most frequently assigned anthropogenic scar codes are consistent with findings from other baleen whale studies. Vessel collision scars were primarily found on the back and dorsal ridge, although parts of the fluke also showed signs of vessel strikes (Fig. 4). These regions, particularly the back, have all been documented to be wounded by vessel strikes in other baleen whale populations (e.g., Kraus 1990, Hamilton et al. 1998, Laist et al. 2001, Panigada et al. 2006). The vulnerability of the baleen whale caudal peduncle to fishing gear entanglement has been well documented (e.g., Heyning and Lewis 1990, Robbins and Mattila 2001, Johnson et al. 2005). This region was most frequently assigned entanglement codes in the present scarring assessment (Fig. 4). Heyning and Lewis (1990) noted that entangled eastern gray whales were most often observed with some or all of the fishing gear around the caudal peduncle and suggested that the netting and line generally slips down the body toward the caudal peduncle, where it gets lodged at the base of the flukes. Although the leading edges of the flukes of some photo-identified western gray whales did show evidence of a previous entanglement (Fig. 4), only the anterior portion of the caudal peduncle was consistently available for scoring (Fig. 3). The reduced availability of the posterior portion of the caudal peduncle including the fluke insertion likely reflects photo-identification protocols as previously discussed, but can also be attributed to the fact that western gray whales do not commonly fluke-up in the study area. This tendency would not only have led to an underestimation of previous entanglement interactions in the present analysis, but may also pose a challenge to future efforts that are needed to systematically assess the susceptibility of western gray whales to entanglement in fishing gear.

The lack of systematic and comprehensive image coverage in the current scarring assessment at the population and individual levels means that precise frequencies and rates of anthropogenic interactions cannot be estimated, nor can the most vulnerable population segments be identified. For example, it is unknown if juvenile western gray whales are more susceptible to entanglement than adult whales, as had been demonstrated for juvenile eastern gray whales (Heyning and Lewis 1990). Although at least 11 of the 28 western gray whales assumed to have been entangled were less than $3 \mathrm{yr}$ of age when their scars were obtained, there is not enough information to evaluate the relative entanglement vulnerability of young whales. Such an evaluation would be valuable, given the low survival documented for western gray whale calves (Bradford et al. 2006). An additional limitation of the present analysis is that the photo-identification effort was limited to the summer months off northeastern Sakhalin Island, Russia. Although the annual timings that were deduced from 
11 anthropogenic interactions usefully imply that these events have been ongoing throughout at least the duration of the photo-identification study, the specific timing and location of most scarring events cannot be determined. A further shortcoming of the scarring assessment is that the precise nature of each type of anthropogenic interaction cannot be specified. While the vessel collision scars detected in the analysis suggest that one of the scarred individuals made contact with a large, possibly ship-sized, vessel and the other two whales with relatively smaller vessels, the diagnostic feature used for such determinations (i.e., propeller cuts) was not well defined in each case. Thus, these designations of vessel collision types cannot be made with confidence. In terms of entanglement scarring, there is no such diagnostic feature, as different kinds or parts of fishing gear can inflict similar injuries.

Finally, quantifying the anthropogenic scarring of free-ranging whales provides information about individuals that survived entanglements and vessel collisions, but not about fatalities. The anthropogenic event percentages presented here indicate that western gray whales are more frequently entangled in fishing gear than struck by vessels. An alternative explanation is that vessel collisions, particularly by ships, are more immediately lethal than entanglements, as has been suggested for North Atlantic right whales (Kraus 1990, Knowlton and Kraus 2001). However, the degree to which western gray whales are struck by ships is not well established to date and the current analysis provides little insight. Although a sighting of a western gray whale off Japan with apparent small boat collision scars was documented prior to this study (Furuta 1984), there are no known reports of western gray whale sightings or strandings linked to collisions with ships. On the other hand, western gray whales are known to be at risk to a highly lethal fishing gear interaction likely not represented in the scarring record. That is, the use of trap nets is pervasive in the coastal waters of Japan and these nets regularly fatally entrap baleen whales (e.g., Tobayama et al. 1992). The previously mentioned fatalities of four female western gray whales between 2005 and 2007 were the result of entrapment in Japanese trap nets (Weller $e t$ al., in press). Until more information is available on the vulnerability of western gray whales to ship strikes, entrapment in trap nets should continue to be regarded as the specific type of anthropogenic interaction leading to the most fatalities of western gray whales.

\section{Significance}

Despite the biases and limitations of the present scarring assessment, the results provide evidence that male and female western gray whales interact with anthropogenic risk factors in some portion of their range (i.e., coastal waters of Russia, Japan, the Korean Peninsula, and China). Thus, the fatal entrapments of four female western gray whales in trap nets off Japan between 2005 and 2007 (Weller et al., in press) were not isolated events. The aforementioned recent individual-based modeling population assessment found that if such annual losses continue, then the population will decline toward extinction (Cooke et al. 2007). As anthropogenic activity is only increasing throughout the range of western gray whales, particularly oil and gas development on and near the feeding ground and industrialization in the migratory corridor (Reeves et al. 2005, IISG 2006), serious concerns are raised about the viability of the population. Future studies designed to systematically and comprehensively monitor anthropogenic scarring of western gray whales are needed to determine if interactions with anthropogenic activity are also increasing. Specifically, 
since 2005 field protocols have been instituted to gather photographic coverage from the anterior portion of the back to the insertion point of the flukes for as many individuals as possible to determine current rates of entanglement and vessel collision, so that increases in these rates can be detected. Additionally, more effort is needed to locate and photograph dead and injured western gray whales throughout their range (Reeves et al. 2005, IISG 2006), but particularly around Japan, where recent strandings and fatalities have been the most numerous (Yamada et al. 2002, Weller et al., in press). Such research is necessary to not only validate and minimize subjectivity in entanglement and vessel collision scar determinations, but more importantly, to better understand and mitigate the impact of anthropogenic interactions on the critically endangered western gray whale population.

\section{ACKNOWLEDGMENTS}

Much appreciation goes to the many participants of the western gray whale photoidentification project. We also thank S. Ashworth and J. Sumich for their preparatory contributions to the scar assessment and M. Marx, J. Neilson, and J. Robbins for their willingness to serve as expert reviewers of the anthropogenic scar determinations. A. Lang and four anonymous referees provided helpful reviews of the manuscript. Support and funding for western gray whales studies have been provided by (in alphabetical order): Alaska SeaLife Center, Animal Welfare Institute, Exxon Neftegas Limited, the International Fund for Animal Welfare, the International Whaling Commission, the Marine Mammal Commission, the Marine Mammal Research Program at Texas A\&M University at Galveston, the National Fish and Wildlife Foundation, the National Marine Fisheries Service, Ocean Park Conservation Foundation Hong Kong, Sakhalin Energy Investment Company, the School of Aquatic and Fishery Sciences at the University of Washington, the U.S. Environmental Protection Agency, and the Washington Cooperative Fish and Wildlife Research Unit. This project was conducted as part of the Marine Mammal Project under Area V: Protection of Nature and the Organization of Reserves within the U.S.-Russia Agreement on Cooperation in the Field of Environmental Protection.

\section{LITERATURE CITED}

Baird, R. W., P. R. Stacey, D. A. Duffus and K. M. Langelier. 2002. An evaluation of gray whale (Eschrichtius robustus) mortality incidental to fishing operations in British Columbia, Canada. Journal of Cetacean Research and Management 4:289-296.

Bradford, A. L., P. R. Wade, D. W. Weller, A. M. Burdin, Y. V. Ivashchenko, G. A. TsidulKo, G. R. VanBlaricom and R. L. Brownell, JR. 2006. Survival estimates of western gray whales Eschrichtius robustus incorporating individual heterogeneity and temporary emigration. Marine Ecology Progress Series 315:293-307.

Bradford, A. L., D. W. Weller, P. R. Wade, A. M. Burdin and R. L. Brownell, Jr. 2008. Population abundance and growth rate of western gray whales Eschrichtius robustus. Endangered Species Research: 16:1-14.

Brownell, R. L., JR., AND C. Chun. 1977. Probable existence of the Korean stock of the gray whale (Eschrichtius robustus). Journal of Mammalogy 58:237-239.

Burdin, A. M, G. A. Tsidulko, Y. V. Ivashchenko, A. L. Bradford and D. W. Weller. 2002. Photo-identification of western gray whales in coastal and offshore Sakhalin shelf waters. Paper SC/02/WGW 4 presented to the International Whaling Commission (unpublished). 6 pp. Available at http://www.iwcoffice.org/.

Cicchetti, D. V., AND A. R. Feinstein. 1990. High agreement but low kappa: II. Resolving the paradoxes. Journal of Clinical Epidemiology 43:551-558. 
CoHEN, J. 1960. A coefficient of agreement for nominal scales. Educational and Psychological Measurement 20:37-46.

Cooke, J. G., D. W. Weller, A. L. Bradford, A. M. Burdin and R. L. Brownell, Jr. 2007. Population assessment of western gray whales in 2007. Paper SC/59/BRG41 presented to the International Whaling Commission (unpublished). $10 \mathrm{pp}$. Available at http://www.iwcoffice.org/.

Feinstein, A. R., AND D. V. CiCCHETTI. 1990. High agreement but low kappa: I. The problems of the two paradoxes. Journal of Clinical Epidemiology 43:543-549.

Fujiwara, M., AND H. Caswell. 2001. Demography of the endangered North Atlantic right whale. Nature 414:537-541.

FurutA, M. 1984. Note on a gray whale found in the Ise Bay on the Pacific coast of Japan. Scientific Reports of the Whales Research Institute Tokyo 35:195-197.

George, J. C., L. M. Philo, K. Hazard, D. Withrow, G. M. Carroll and R. Suydam. 1994. Frequency of killer whale (Orcinus orca) attacks and ship collisions based on scarring on bowhead whales (Balaena mysticetus) of the Bering-Chukchi-Beaufort Seas stock. Arctic 47:247-255.

Hamilton, P. K., M. K. Marx and S. D. Kraus. 1998. Scarification analysis of North Atlantic right whales (Eubalaena glacialis) as a method of assessing human impacts. Report to the Northeast Fisheries Science Center, National Marine Fisheries Service, Contract No. 46EANF60004 (unpublished). 39 pp. Available from the New England Aquarium, Central Wharf, Boston, MA 02110, U.S.A.

HeYNING, J. E., AND T. D. LeWIS. 1990. Entanglements of baleen whales in fishing gear off southern California. Report of the International Whaling Commission 40:427-431.

Hilton-TAYLOR, C. 2000. IUCN red list of threatened species. Species Survival Commission, IUCN, Gland, Switzerland.

IISG. 2006. Report of the Interim Independent Scientists Group (IISG) on mitigation measures to protect western gray whales during Sakhalin II construction operations in 2006, Vancouver, British Columbia, 3-5 April 2006. Business and Biodiversity Program, IUCN. 24 pp. Available at http://www.iucn.org/.

Johnson, A., G. Salvador, J. Kenney, J. Robbins, S. Kraus, S. Landry and P. Clapham. 2005. Fishing gear involved in entanglements of right and humpback whales. Marine Mammal Science 21:635-645.

KNOWLTON, A. R., AND S. D. Kraus. 2001. Mortality and serious injury of northern right whales (Eubalaena glacialis) in the western North Atlantic Ocean. Journal of Cetacean Research and Management (Special Issue) 2:193-208.

Knowlton, A. R., M. K. Marx, H. M. Pettis, P. K. Hamilton and S. D. Kraus. 2005. Analysis of scarring on North Atlantic right whales (Eubalaena glacialis): Monitoring rates of entanglement interaction: 1980-2002. Report to the Northeast Fisheries Science Center, National Marine Fisheries Service, Contract No. 43EANF030107 (unpublished). 20 pp. Available from the New England Aquarium, Central Wharf, Boston, MA 02110. U.S.A.

Kraus, S. D. 1990. Rates and potential causes of mortality in North Atlantic right whales (Eubalaena glacialis). Marine Mammal Science 6:278-291.

Kraus, S. D., M. W. Brown, H. Caswell, C. W. Clark, M. Fujiwara, P. K. Hamilton, R. D. Kenney, A. R. Knowlton, S. Landry, C. A. Mayo, W. A. Mclellan, M. J. Moore, D. P. NowaceK, D. A. Pabst, A. J. Read and R. M. Rolland. 2005. North Atlantic right whales in crisis. Science 309:561-562.

Laist, D. W., A. R. Knowlton, J. G. Mead, A. S. Collet and M. Podesta. 2001. Collisions between ships and whales. Marine Mammal Science 17:35-75.

LIEN, J. 1994. Entrapments of large cetaceans in passive inshore fishing gear in Newfoundland and Labrador (1979-1990). Report of the International Whaling Commission (Special Issue 15):149-157.

Moore, M. J., A. R. Knowlton, S. D. Kraus, W. A. Mclellan and R. K. Bonde. 2004. Morphometry, gross morphology and available histopathology in North Atlantic right 
whale (Eubalaena glacialis) mortalities (1970-2002). Journal of Cetacean Research and Management 6:199-214.

NeiLSON, J. N. 2006. Humpback whale (Megaptera novaeangliae) entanglements in fishing gear in northern southeastern Alaska. M.Sc. thesis, University of Alaska Fairbanks, Fairbanks, AK. 118 pp.

Panigada, S., G. Pesante, M. Zanardelli, F. Capollade, A. Gannier and M. T. Weinrich. 2006. Mediterranean fin whales at risk from fatal ship strikes. Marine Pollution Bulletin 52:1287-1298.

Philo, L. M., J. C. George And T. F. Albert. 1992. Rope entanglement of bowhead whales (Balaena mysticetus). Marine Mammal Science 8:306-311.

Reeves, R. R., R. L. Brownell, Jr., A. M. Burdin, J. C. Cooke, J. D. Darling, G. P. Donovan, F. M. D. Gulland, S. E. Moore, D. P. Nowacek, T. J. Ragen, R. G. Steiner, G. R. VanBlaricom, A. I. Vedenev and A. V. Yablokov. 2005. Report of the Independent Scientific Review Panel on the impacts of Sakhalin II Phase 2 on western North Pacific gray whales and related biodiversity. IUCN, Gland, Switzerland. 123 pp. Available at http://www.iucn.org/.

Robbins, J., AND D. K. MATTILA. 2001. Monitoring entanglements of humpback whales (Megaptera novaeangliae) in the Gulf of Maine on the basis of caudal peduncle scarring. Paper SC/53/NAH25 presented to the International Whaling Commission (unpublished). 14 pp. Available at http://www.iwcoffice.org/.

RobBins, J., AND D. K. MATTILA. 2004. Estimating humpback whale (Megaptera novaeangliae) entanglement rates on the basis of scar evidence. Report to the Northeast Fisheries Science Center, National Marine Fisheries Service, Contract No. 43EANF030121 (unpublished). 21 pp. Available from the Center for Coastal Studies, Box 1036, Provincetown, MA 02657, U.S.A.

SimONOFF, J. S. 2003. Analyzing categorical data. Springer, New York, NY.

SuMICH, J. L., AND J. T. HARVEY. 1986. Juvenile mortality in gray whales (Eschrichtius robustus). Journal of Mammalogy 67:179-182.

TOBAYAMA, T., F. YANAGISAWA AND T. KasuYA. 1992. Incidental take of minke whales in Japanese trap nets. Report of the International Whaling Commission 42:433-436.

VolgenAu, L., S. D. Kraus AND J. Lien. 1995. The impact of entanglements on two substocks of the western North Atlantic humpback whale, Megaptera novaeangliae. Canadian Journal of Zoology 73:1689-1698.

Weller, D. W., A. L. Bradford, H. Kato, T. Bando, S. Otani, A. M. Burdin and R. L. BROWNELL, JR. In press. A photographic match of a western gray whale between Sakhalin Island, Russia, and Honshu, Japan: The first link between the feeding ground and a migratory corridor. Journal of Cetacean Research and Management.

Weller, D. W., A. M. Burdin, B. WÜrsig, B. L. TAylor and R. L. Brownell, JR. 2002. The western Pacific gray whale: A review of past exploitation, current status and potential threats. Journal of Cetacean Research and Management 4:7-12.

Weller D. W., A. M. Burdin, A. L. Bradford, A. R. Lang, G. A. Tsidulko, H. W. Kim AND R. L. BROWNELL, JR. 2006. Status of western gray whales off northeastern Sakhalin Island, Russia, in 2005. Paper SC/58/BRG3 presented to the International Whaling Commission (unpublished). $10 \mathrm{pp}$. Available at http://www.iwcoffice.org/.

Weller, D. W., B. Würsig, A. L. Bradford, A. M. Burdin, S. A. Blokhin, H. Minakuchi AND R. L. BROwNelL, JR. 1999. Gray whales (Eschrichtius robustus) off Sakhalin Island, Russia: Seasonal and annual patterns of occurrence. Marine Mammal Science 15:12081227.

YAmAdA, T. K., Y. Uni and H. IshiKaWA. 2002. Recent gray whale strandings and sightings around Japan. Paper SC/02/WGW8 presented to the International Whaling Commission (unpublished). 5 pp. Available at http://www.iwcoffice.org/. 